\title{
Rational Design of Organo-Ruthenium Anticancer Compounds
}

\author{
Christian Gossens§, Ivano Tavernelli, and Ursula Rothlisberger* \\ $\S$ Mettler Toledo Award Winner (Oral Presentation)
}

\begin{abstract}
Organometallic ruthenium(II)-arene complexes are currently attracting increasing interest as anticancer compounds with the potential to overcome drawbacks of traditional drugs like cisplatin with respect to resistance, selectivity, and toxicity. Rational design of new potential pharmaceutical compounds requires a detailed understanding of structure-property relationships at an atomic level. We performed in vacuo density functional theory (DFT) calculations, classical MD, and mixed QM/MM Car-Parrinello MD explicit solvent simulations to rationalize the binding mode of two series of anticancer ruthenium(II) arene complexes to double-stranded DNA (dsDNA). Binding energies between the metal centers and the surrounding ligands as well as proton affinities were calculated using DFT. Our results support a $\mathrm{pH}$-dependent mechanism for the activity of the RAPTA $\left[\mathrm{Ru}\left(\eta^{6}-\mathrm{arene}\right) \mathrm{X}_{2}(\mathrm{pta})\right]$ (pta = 1,3,5-triaza-7-phosphatricyclo[3.3.1.1]decane) compounds. Adducts of the bifunctional RAPTA and the monofunctional $\left[R u\left(\eta^{6}-p\right.\right.$-cymene)Xen] ${ }^{+}$series of compounds with the DNA sequence $d\left(C C T C T G^{*} G^{*} T C T C C\right) /$ $\mathrm{d}\left(\mathrm{GGAGACCAGAGG)}\right.$, where $\mathrm{G}^{*}$ are guanosine bases that bind to the ruthenium compounds through their $\mathrm{N}(7)$ atom, have been investigated. The resulting binding sites were characterized in $\mathrm{QM} / \mathrm{MM}$ molecular dynamics simulations showing that DNA can easily adapt to accommodate the ruthenium compounds.
\end{abstract}

Keywords: Cancer · Computational chemistry · DFT · Molecular dynamics · Organo-ruthenium

\section{Introduction}

The discovery of cisplatin $\left[\mathrm{Pt}\left(\mathrm{NH}_{3}\right)_{2} \mathrm{Cl}_{2}\right]$ as an anticancer drug by Rosenberg et al. in 1965 [1] led to considerable interest in metallopharmaceuticals [2]. However, problems remain associated with their use, including general toxicity, drug resistance and low selectivity. Today, cisplatin [3] still represents the most widely used anticancer drug and is employed in the treatment of approximately $70 \%$ of all cancer patients. Although the mechanism by which such compounds exert their medicinal effect is little understood and still remains a matter of debate, DNA interactions are generally considered to be critical. Recently, organometallic ruthenium(II) complexes have shown their potential to overcome some of the drawbacks [4].

The most detailed study on ruthenium(II) arenes has been undertaken for $\left[\mathrm{Ru}\left(\eta^{6}-\right.\right.$ arene $) \mathrm{Cl}($ dien $)]^{+}$complexes containing the chelating ethylenediamine (dien) ligand [5]. These complexes bind preferably to $\mathrm{N}(7)$ of guanine bases. The selectivity appears to be controlled by the ethylenediamine $\mathrm{NH}_{2}$ groups, which hydrogen-bond with exocyclic oxygens, but are nonbonding and repulsive toward the exocyclic amino groups of the nucleobases. For extended aromatic ligands intercalation was shown to accelerate binding to DNA.

Another promising anticancer compound was synthesized by combining ruthenium(II)-arene complexes with the 1,3,5-triaza-7-phosphatricyclo-[3.3.1.1] decane (pta) ligand [6]. The compound $\left[\mathrm{Ru}\left(\eta^{6}\right.\right.$ - $p$-cymene $) \mathrm{Cl}_{2}$ (pta) $](\mathbf{1}=\mathrm{RAPTA}$ C, Fig. 1) was found to exhibit $\mathrm{pH}-$ dependent DNA damage. At the $\mathrm{pH}$ typical of hypoxic cells DNA was damaged, whereas at the $\mathrm{pH}$ characteristic of healthy cells, little or no damage was detected. This behavior was ascribed to the pta ligand which can be
${ }^{*}$ Correspondence: Prof. Dr. U. Rothlisberger Laboratory of Computational Chemistry and Biochemistry

Institut des Sciences et Ingénierie Chimiques

Ecole Polytechnique Fédérale de Lausanne

EPFL-BCH

$\mathrm{CH}-1015$ Lausanne

Tel: + 41216930321

Fax: + 41216930320

E-Mail: ursula.roethlisberger@epfl.ch

http://lcbcpc21.epfl.ch

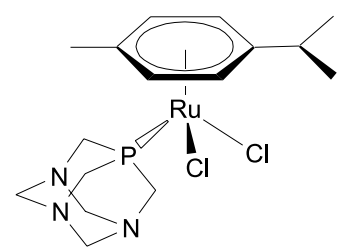

1

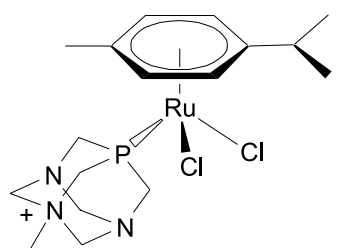

2

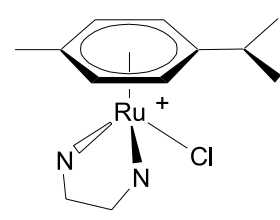

3
Fig. 1. Ruthenium(II)-arene complexes studied 
protonated at low $\mathrm{pH}$, and the protonated form was considered to be the active agent. Subsequently, it has been demonstrated that 1 exhibits highly selective anticancer activity in cell culture, destroying cancer cells while having almost no observable effect on healthy cells. In contrast, the model compound for the protonated derivative, $\left[\mathrm{Ru}\left(\eta^{6}-p \text {-cymene }\right) \mathrm{Cl}_{2}(\text { pta-Me })\right]^{+}$(2), has an indistinguishable toxicity against both cancer and healthy cells. However, little is as yet understood concerning the mode of binding to DNA at the molecular level and the structural changes induced by this perturbation, information that is critical for the rational drug design and optimization.

Computational chemistry can help to obtain a detailed understanding of structureproperty relationships at the atomic level. We have started to investigate the above mentioned ruthenium(II) arene complexes using classical molecular mechanics (MM) [7], quantum mechanics (QM) [8][9] and a combined quantum/classical (QM/MM) approach that has been recently developed in our group [10]. Molecular dynamics (MD) in aqueous solution provides insight on how the system responds over time to an external perturbation. Focusing on dsDNA we try to rationalize the binding mode of the RAPTA and related compounds with the final goal to rationally design substances with increased efficiency and selectivity. Cisplatin and $\left[\mathrm{Ru}\left(\eta^{6}-p\right.\right.$-cymene $)$ Cldien $]$ (3) are both known to bind preferentially to $\mathrm{N}(7)$ of guanine in dsDNA. Based on a crystal structure of a cisplatin 1,2-intra-strand adduct to duplex DNA [11] we docked the monofunctional 3 and the bifunctional RAPTA $\left[\mathrm{Ru}\left(\eta^{6}\right.\right.$-arene $\left.) \mathrm{Cl}_{2}(\mathrm{pta})\right]$ (4) series of compounds to the major groove of the DNA sequence d(CCTCTG*G*TCTCC)/ d(GGAGACCAGAGG), where $\mathrm{G}^{*}$ are guanosine bases that coordinate to the ruthenium compounds through $\mathrm{N}(7)$ by replacing the halogen ions.

In this paper we summarize some recent results obtained from our still ongoing computational studies on ruthenium(II)-arene complexes and the structural, electronic, and chemical properties of their DNA adducts.

\section{Methods}

DFT gas-phase calculations were performed using the Gaussian03 [8] and ADF2004 [9] packages. For Gaussian03 the B3LYP functional was employed together with either the LanL2DZ (method 1) or SDD (method 2) ECP for ruthenium and the $6-31+\mathrm{G}(\mathrm{d})$ basis set for the remaining atoms. ADF calculations were carried out using the BP86 functional together with the TZP/Zora basis set (method 3). For more details and comparison of the resulting numbers see [12].
Classical molecular dynamics were carried out using the Amber force field (parm99; timestep 1-1.5fs; 298K) [7]. The initial configuration was obtained by replacing the cisplatin 1,2-intra-strand dsDNA major groove adduct in [11] by ruthenium(II) arenes. Classical parameterization for two compounds out of the RAPTA series $\left(\eta^{6}\right.$-arene: $\mathrm{B}=$ benzene, $\mathrm{C}$ $=p$-cymene) and compound $\mathbf{3}$ have been realized following the Amber procedure. As reference, the same DNA sequence was also simulated in a setup where cisplatin was completely removed in order to study the relaxation of the DNA towards its unperturbed B-DNA form, which has been simulated as well. Mixed QM/MM CarParrinello MD simulations were performed starting from classically equilibrated structures. The BLYP functional with an energy cut-off of 75 Rydberg and a timestep of 4 a.u. at $298 \mathrm{~K}$ was employed.

\section{Selected Results and Discussion}

\section{pH-Independent Model}

It is generally assumed that cancer tissue is more acidic than healthy tissue. Experimentally, the N-methylated compound 2 is used as a $\mathrm{pH}$-independent model for the $\mathrm{N}$-protonated species $\mathbf{1}-\mathbf{H}^{+}$of compound $\mathbf{1}$ which is currently thought to be responsible for the selective cytotoxicity for cancer cells. Using method 2 we calculated the ruthenium $p$-cymene binding interactions of the two compounds $\mathbf{2}$ and $\mathbf{1}-\mathbf{H}^{+}$to be 31.7 and $32.0 \mathrm{kcal} / \mathrm{mol}$, respectively whereas the corresponding ruthenium pta binding energies turn out to be 17.9 and $18.4 \mathrm{kcal} / \mathrm{mol}$, respectively [12]. Orbital energies (e.g. HOMO: -0.3076 vs. -0.3096 a.u.) and geometries are also nearly identical, and only the slightly higher steric demand of the methyl-group might discriminate between these two compounds. These findings support the experimental use of $\mathbf{2}$ as a $\mathrm{pH}$-independent model compound for $\mathbf{1}$ in a more acidic environment.

\section{Proton Affinities}

The protonation state of the pta ligand in cancer tissue is of particular interest [6]. The pta ligand might get protonated in the slightly more acidic environment of cancer tissue exhibiting different properties compared to the unprotonated state. Using method 2 we estimated in vacuo proton af-

Table 1. Experimental $\mathrm{pK}_{\mathrm{a}}$ and calculated proton affinities [kcal/mol]

\begin{tabular}{|llllll} 
& $\mathrm{pta} / \mathrm{H}^{+}$ & $\mathrm{nta} / \mathrm{H}^{+}$ & $\mathrm{pta}=\mathrm{O} / \mathrm{H}^{+}$ & $\mathrm{RAPTA}-\mathrm{B} / \mathrm{H}^{+}$ & RAPTA-C/H \\
\hline Exp. pK & $5.7-6.1$ & 4.89 & 2.52 & n.a. & n.a. \\
$\mathrm{H}^{+}$affinity: B3LYP & 234.6 & 233.4 & 225.6 & 235.6 & 234.5
\end{tabular}

finities as the energy differences $\mathrm{E}_{\mathrm{OK}}(\mathrm{B})-$ $\mathrm{E}_{0 \mathrm{~K}}\left(\mathrm{BH}^{+}\right)$of the not yet defined RAPTA-B/ $\mathrm{C}$ compounds. As reference the values for the isolated pta ligand and two of its derivatives were calculated as their experimental $\mathrm{pK}_{\mathrm{a}}$ is known. We found good agreement of $\mathrm{pK}_{\mathrm{a}}$ values and proton affinities (Table 1). In agreement with experiment, the pta ligand turned out to be more basic than hexamethylenetetramine (nta) or the oxidized pta derivative $(\mathrm{pta}=\mathrm{O})$ [13]. For all pta derivatives the nitrogen atom turns out to be the most basic site of the molecule. As a main conclusion of our calculations, we can expect the RAPTA series to have $\mathrm{pK}_{\mathrm{a}}$ values similar to those of the isolated pta ligand. This result is in good agreement with experiments carried out by Laurenczy and coworkers [14] who observed notable protonation of the pta ligand below $\mathrm{pH}=$ 6.5 when synthesizing $\mathrm{Ru}(\mathrm{II})\left(\mathrm{H}_{2} \mathrm{O}\right)_{\mathrm{x}}(\mathrm{pta})_{\mathrm{y}}$ species.

\section{ssDNA}

Experimentally, it was also shown that RAPTA compounds can lose their arene ligand when reacting with single stranded ssDNA while DFT calculation showed that it is very unlikely that the arene is replaced by a $\pi$-bound nucleobase [12]. Our results suggest the formation of an adduct in which the freed arene-ruthenium coordination sites are occupied by nucleobases that are $\sigma$-bonded via their nitrogen atoms. In this model the highly flexible ssDNA should wrap around the ruthenium center to occupy five coordination sites in the octahedral adduct leaving only the pta ligand unchanged. In order to gain an understanding of the observed arene loss we calculated (method 1) the potential energy as a function of ruthenium-ligand distance (Fig. 2). This shows that the benzene is bound in a stiffer way than the pta ligand but that the interaction decays more rapidly than the ruthenium-pta interaction. Using $\mathrm{H}_{2} \mathrm{O}$ as a probe ligand which coordinates to the ruthenium center in RAPTA-B between the two chlorides, we identified different intermediates that are likely to be involved in the mechanism of arene loss. Constraining the water oxygen to bind to ruthenium we observed in geometry optimization runs that the arene reduces hapticity from $\eta^{6}$ to $\eta^{4}$ to $\eta^{2}$ coordination while chloride and pta ligands are not affected. We calculated (method 3 ) the $\eta^{4}$ intermediate to be $13.3 \mathrm{kcal} / \mathrm{mol}$ and the $\eta^{2}$ intermediate to be 14.1 and $14.9 \mathrm{kcal} / \mathrm{mol}$ (two conformations observed) less stable than in 


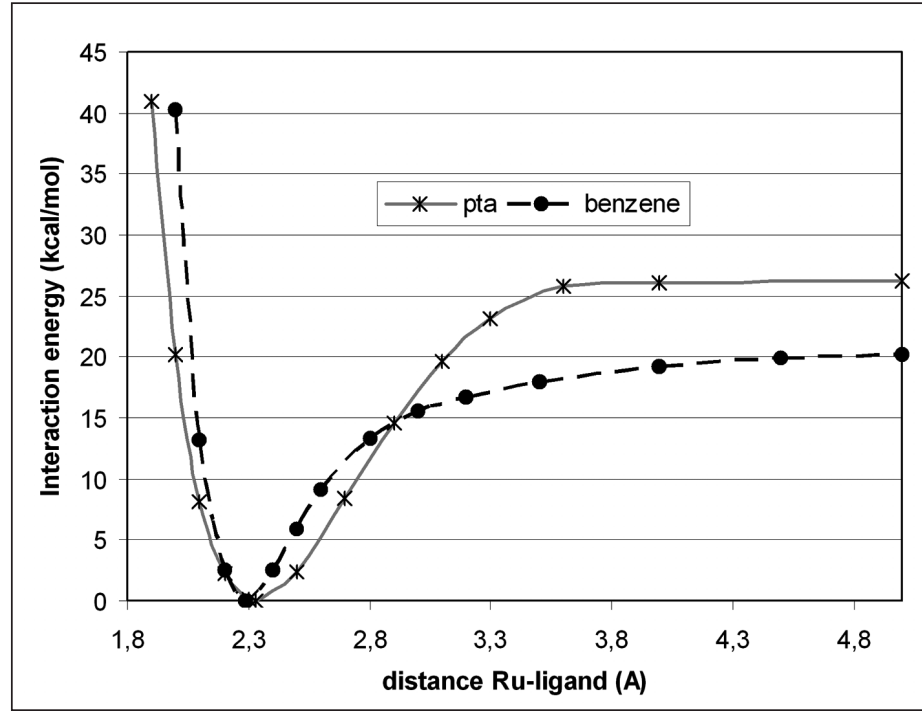

Fig. 2. Potential energy as a function of the ruthenium-ligand distance

Table 2. Ligand binding energies $[\mathrm{kcal} / \mathrm{mol}]$ for aqua and guanine complexes

$\begin{array}{llll}\text { Ligand } \mathrm{Y} & {[\mathrm{Ru}(\text { benzene }) \mathrm{Cl}(\mathrm{pta}) \mathrm{Y}]^{+}} & {\left[\mathrm{Ru}(\text { benzene })(\mathrm{pta}) \mathrm{Y}_{2}\right]^{2+}} & {\left[\mathrm{Ru}(\text { p-cymene)dienY }]^{2+}\right.} \\ \mathrm{H}_{2} \mathrm{O} & 16.4 & 52.1 & 25.0 \\ \text { Guanine } & 35.0 & 107.6 & 60.8\end{array}$

the case of the $\eta^{6}$ coordination. The binding energy of benzene in the $\eta^{2}$ intermediate was calculated to be $15.5 \mathrm{kcal} / \mathrm{mol}$. As reported in [12], the binding energy of e.g. guanine bound via $\mathrm{N}(7)$ to the $\left[\mathrm{RuCl}_{2} \mathrm{pta}\right]$ fragment is of the order of $22.3 \mathrm{kcal} / \mathrm{mol}$. From these preliminary results we can envisage a model in which, assuming an associative mechanism, first an energy barrier has to be overcome in order to displace the arene but in a second step, the sum of five $\sigma$ bonds may compensate for the loss of the $\eta^{6}$ coordinated arene.

\section{dsDNA}

Experimentally, the loss of arene is not observed in the reaction with single nucleosides and moreover, also for ssDNA this phenomena decreases with an increase of RAPTA concentration. It is also worth mentioning that inside a cell, DNA is present most of the time as a double strand (dsDNA). Assuming that this is the most important target for the RAPTA compounds, the only readily accessible nitrogen donor atoms are $\mathrm{N}(7)$ of adenine and guanine [15]. This is because none of the strands has the flexibility to wrap around a ruthenium coordination centre without breaking an extensive number of Watson-Crick hydrogen bonds. As the guanine N(7) site is known to be highly nucleophilic and to constitute the main target also for other anti-cancer compounds like cisplatin [15] and 3 [5], we further focused our analysis on this type of interaction. All investigated compounds are known to undergo hydrolysis at low chlo- ride concentration, typical for inside cells. We therefore calculated (model 1) in vacuo the binding energies for both the aqua species and the guanine N(7) adducts (Table $2)$. All investigated compounds show significant higher binding energies for the interaction with guanine compared to water.
Moreover, the replacement of both aqua ligands by $\mathrm{N}(7)$-bound guanine ligands is more favorable.

Based on a molecular graphics investigation of $\left[\mathrm{Cp}_{2} \mathrm{M}\right]^{2+}$ coordination to a model oligonucleotide duplex, Marks and coworkers argued against cisplatin-like $\mathrm{d}(\mathrm{pGpG})$ complexation motifs [16]. This led to the widespread perception that transition metal arene compounds with two bulky ligands cannot bind to the major groove of DNA. However, using QM/MM molecular dynamics we could show that both investigated ruthenium compounds $\mathbf{3}$ and $\mathbf{4}$ can bind to the major groove and are stable in this position. We docked the ruthenium compounds in a cisplatin-like fashion and relaxed the DNA and the surrounding explicit water molecules and counter-ions. The DNA is highly flexible, adapts very fast and widens to accommodate the ruthenium complex. Upon this first equilibration, we let the full system evolve freely in time, describing at the quantum level the ruthenium complex as well as the two guanine bases that it binds to, while describing the rest of the DNA and the surrounding solvent in a classical scheme (Fig. 3). The local and global structural changes of the DNA observed for the RAPTA series are similar to those reported for cisplatin [17]. Using a parameterization of the ruthenium complexes, derived from DFT in vacuo and verified by QM/MM explicit solvent simulations, we used classical MD to extend the time scale of our investigation. Whereas we did not observe any dramatic conformational changes in the case
Fig. 3. Snapshot of the QM/MM system showing RAPTA-B bound to dsDNA. Only water molecules within 5 Å of RAPTA-B are shown explicitly (rest omitted for clarity).

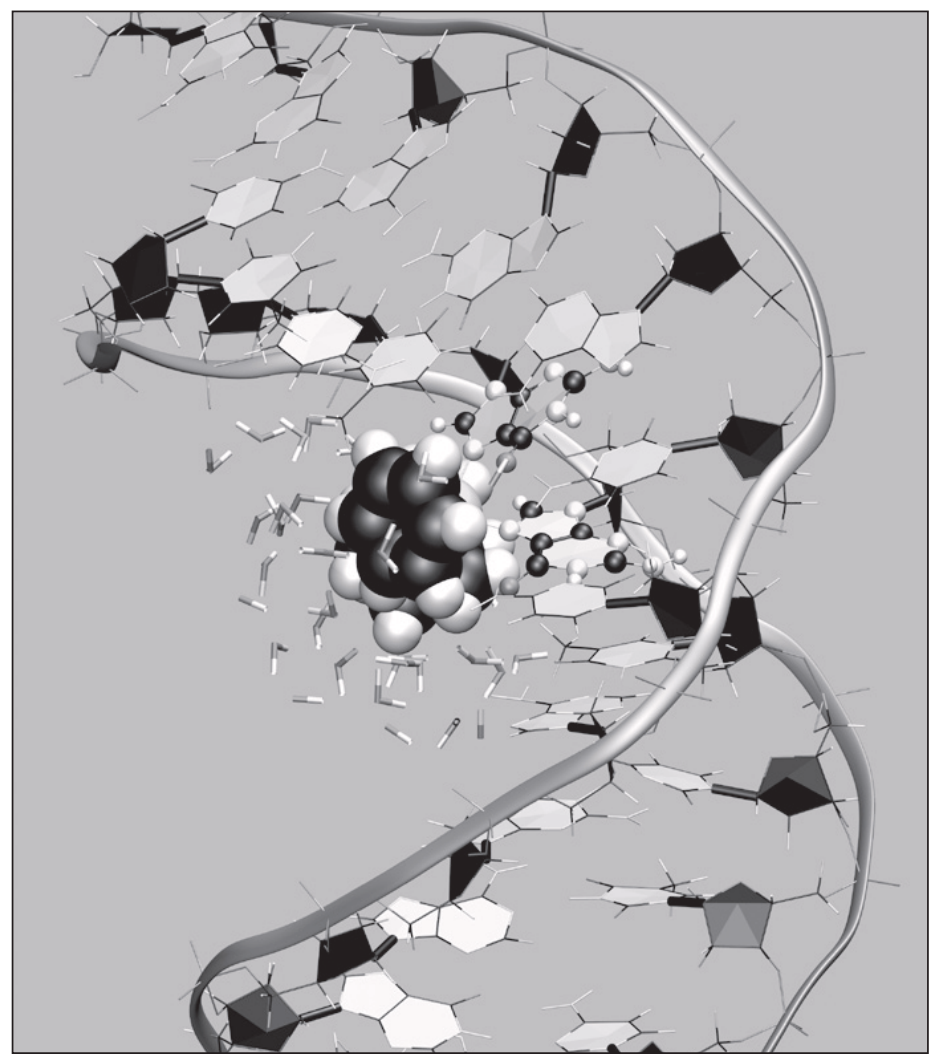


of the RAPTA compounds, we observed a severe perturbation of the Watson-Crick base pairing adjacent to the binding site of 3 [18]. This phenomena of hydrogen-bond breaking was also observed experimentally [19]. We are currently working on a detailed analysis of this process.

\section{Conclusions and Perspectives}

Computational chemistry can provide insight on the atomic level, assist the interpretation of experiments and help developing working hypothesis for further experimental work. Our first results for the RAPTA compounds show that methylated pta is a good pH-independent model for protonated pta and that it is likely that this ligand is protonated in a slightly acidic environment. Loss of arene, although this is possible with ssDNA assisted by nucleobases binding through $\sigma$ bonds, is unlikely to occur with dsDNA. Binding to the major groove of dsDNA via two adjacent guanine $\mathrm{N}(7)$ was shown to be stable at a QM/MM MD level of theory.

The influence of the protonated pta upon DNA binding has still to be investigated. With the help of the atomic picture that we have obtained we hope to get a deeper understanding of the mechanism of the anticancer activity exhibited by the ruthenium compounds.

\section{Acknowledgement}

We wish to thank Prof. P. Dyson, A. Dorcier, and C. Scolaro for providing us with experimental results prior to publication. Support from the Swiss National Science Foundation (Grant No 200021-100242/1) is gratefully acknowledged.

Received: January 6, 2005
[1] B. Rosenberg, L. Vancamp, T. Krigas, $\mathrm{Na}$ ture 1965, 205, 698.

[2] M.J. Clarke, F. Zhu, D.R. Frasca, Chem. Rev. 1999, 99, 2511; E. Wong, C.M. Giandomenico, Chem. Rev. 1999, 99, 2451.

[3] M.A. Fuertes, C. Alonso, J.M. Perez, Chem. Rev. 2003, 103, 645.

[4] G. Sava, I. Capozzi, A. Bergamo, R. Gagliardi, M. Cocchietto, L. Masiero, M. Onisto, E. Alessio, G. Mestroni, S. Garbisa, Int. J. Cancer 1996, 68, 60; M. Galanski, V.B. Arion, M.A. Jakupec, B.K. Keppler, Pharm. Des. 2003, 9, 2078.

[5] R.E. Aird, J. Cummings, A. Ritchie, M. Muir, R. Morris, H. Chen, P.J. Sadler, D.I. Jodrell, Br. J. Cancer 2002, 86, 1652; H. Chen, J.A. Parkinson, R.E. Morris, P.J. Sadler, J. Am. Chem. Soc. 2003, 125, 173; H. Chen, J.A. Parkinson, S. Parsons, R.A. Coxall, R.O. Gould, P.J. Sadler, J. Am. Chem. Soc. 2002, 124, 3064; R. Morris, A. Habtemariam, Z. Guo, S. Parsons, P.J. Sadler Inorg. Chim. Acta 2002, 339, 551; R.E. Morris, R.E. Aird, P.d.S. Murdoch, H. Chen, J. Cummings, N.D. Hughes, S. Parsons, A. Parkin, G. Boyd, D.I. Jodrell, P.J. Sadler, J. Med. Chem. 2001, 44, 3616; F. Wang, H. Chen, J.A. Parkinson, P.d.S Murdoch, P.J. Sadler, Inorg. Chem. 2002, 41, 4509; F. Wang, H. Chen, S. Parsons, I.D.H. Oswald, J.E. Davidson, P.J. Sadler, Chem. Eur. J. 2003, 9, 5810; [20].

[6] C.S. Allardyce, P.J. Dyson, D.J. Ellis, S.L. Heath, Chem. Commun. 2001, 1396; C.S. Allardyce, P.J. Dyson, D.J. Ellis, P.A. Salter, R. Scopelliti, J. Organomet. Chem. 2003, 668, 35.

[7] P.A. Kollman et al. (2004), AMBER 8, University of California, San Francisco.

[8] J.A. Pople et al., Gaussian 03, Revision B.03; Gaussian, Inc.: Pittsburgh PA, 2003.

[9] ADF2004.01, SCM: Vrije Universiteit, Amsterdam, The Netherlands, 2004.
[10] A. Laio, J. VandeVondele, U. Rothlisberger J. Chem. Phys. 2002, 116, 6941.

[11] P.M. Takahara, C.A. Frederick, S.J. Lippard, J. Am. Chem. Soc. 1996, 118, 12309.

[12] A. Dorcier, P.J. Dyson, C. Gossens, U. Rothlisberger, R. Scopelliti, I. Tavernelli manuscript accepted for Organometallics.

[13] D.J. Darensbourg, J.B. Robertson, D.L. Larkins, J.H. Reibenspies, Inorg. Chem. 1999, 38, 2473.

[14] J. Kovacs, F. Joo, A.C. Benyei, G. Laurenczy, J. Chem Soc. Dalton Trans. 2004, 2336.

[15] J. Reedijk, Chem. Commun. 1996, 801.

[16] L.Y. Kuo, M.G. Kanatzidis, M. Sabat, A.L. Tipton, T.J. Marks, J. Am. Chem. Soc. 1991, 113, 9027.

[17] K. Spiegel, U. Rothlisberger, P. Carloni, $J$. Phys. Chem. B 2004, 108, 2699.

[18] C. Gossens, I. Tavernelli, U. Rothlisberger, manuscript in preparation.

[19] O. Novakova, H. Chen, O. Vrana, A. Rodger, P.J. Sadler, V. Brabec, Biochemistry 2003, 42, 11544. 